\title{
Characterization of electrodeposited zinc oxide/tetrasulphonatedcopper phthalocyanines (ZnO/Ts-CuPc) hybrid films and their photoelectrochemical properties
}

\author{
Bernabé Marí , Monica M. Moya , Krishan C. Singh , Miquel Mollar , Pablo Palacios , \\ Emilio Artacho , Perla Wahnón
}

\begin{abstract}
A B S T R A C T
Hybrid films of zinc oxide ( $\mathrm{ZnO}$ ) and tetrasulphonatedcopper phthalocyanine (Ts-CuPc) have been prepared by cathodic electro-deposition from aqueous $\mathrm{O}_{2}$-saturated solutions of $\mathrm{ZnCl}_{2}$ and Ts-CuPc. The Ts-CuPc content of the films can be varied in a wide range by variation of dye concentration in the electro-deposition bath - from single Ts-CuPc molecules embedded in compact crystalline ZnO to films based on an amorphous Ts-CuPc framework. With increasing dye content the colour of the films changes from light blue to deep blue. All films were characterized by XRD, SEM and AFM. Photoelectro-chemical characteristics of the electrodes were studied by photocurrent spectra and by time-resolved photocurrent measurements in $0.1 \mathrm{M} \mathrm{KCl}$ electrolyte. At the same time, changes in the electrical and photoelectrical properties of the films are observed, enabling the tuning of these properties in view of optoelectronic applications. Theoretical calculations based on density functional theory (DFT) models were made to understand the optoelectronic properties of the hybrid films. Different parallel and perpendicular orientations were tested. For the most stable hybrid structure, total and projected densities of states of the system were obtained and the alignment of the levels observed.
\end{abstract}

\section{Introduction}

Recently metallo-phthalocyanines complexes have attracted much attention due to their application indifferent areas such as display devices, data storage, solar cell, photo-reduction of water to hydrogen and other UV-vis light driven process [1-3], as well as their role in the photodynamic therapy of cancer [4,5]. Metallo-phthalocyanines such as copper or zinc-phthalocyanines complexes are promising materials for dye-sensitized photoelectrochemical solar cell. The conversion of solar energy into electricity is based on nano-porous-nano-crystalline photo-electrode [6-8]. In such cell, light absorption of the dye is followed by electron injection from the excited adsorbed dye into the conduction band of the semiconductor; the electrons are brought back to the oxidized dye through an external way using a counter electrode (Pt) and a redox system. It is desirable that a dye to be used as a sensitizer [9,17]; should absorb light in the whole solar spectrum, with energy of its lowest unoccupied molecular orbital (LUMO) higher than the conduction band edge of the semiconductor. Also the dye should be attached strongly to the semiconductor surface to allow the fast electron injection into the conduction band with a quantum yield of unity. It is known that through dye-sensitization of a wide gap semiconductors, like $\mathrm{TiO}_{2}$ or $\mathrm{ZnO}$, electron can be injected from the excited state of the dye into the semiconductors [10-17], some of the systems investigated are merocyanines- $\mathrm{ZnO}$ [18], $\mathrm{CuPc} / \mathrm{TiO}_{2}$ and $\mathrm{TiO}_{2} / \mathrm{ZnPc}$ [19]. For a recent review see Ref. [20]. These devices were investigated in the form of bilayer devices. In bilayer heterojunction devices, the photoelectrons generated in organic dye diffuse to the dye/oxide interface in order to achieve charge separation. But the photovoltaic efficiency is limited due to the short diffusion length of excitons (less than $10 \mathrm{~nm}$ ) in the organic dye. The efficiency of these devices can further be increased by the proper choice of optical band gap and right alignment of donor acceptor molecular orbital. The former will lead to more overlapping with solar spectrum and the latter will result in higher open circuit voltage. In recent years one-step electrodeposition of nanostructured $\mathrm{ZnO} /$ dye hybrid films on transparent conducting substrates such as glass covered with ITO or FTO have been deposited and characterized [21-23]. Especially 


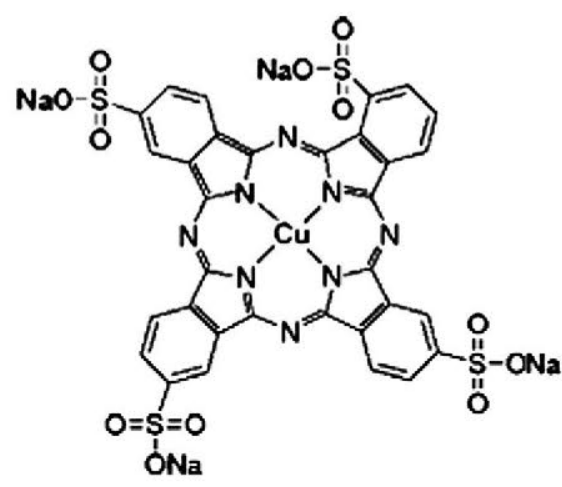

Fig. 1. Structural formula of $1 \alpha 3 \beta\left(\mathrm{NaSO}_{3}\right) \mathrm{CuPc}$.

dye molecules with carboxylic or sulphonic acid groups were found to adsorb strongly on the growing $\mathrm{ZnO}$ surface, leading to their co-deposition and a significant influence on the morphology and crystallographic orientation of the $\mathrm{ZnO}$ [21,23-26]. The most prominent example is the dye eosin Y, which leads to highly porous and sponge-like $\mathrm{ZnO}$ structures that can be described as porous single crystals and proved to be very efficient in dye sensitized solar cells $[21,23]$. Beside organic dye molecules, tetrasulphonated metal phthalocyanines (Ts-MePc) (Fig. 1) with Zn, Alor Si as metals were also co-deposited with ZnO [24-27]. These films also exhibited some porosity of the $\mathrm{ZnO}$ framework, so that the Ts-MePc could act as photo-sensitizers in photo-electrochemical measurements.

In this paper, nanoporous and nanocrystalline hybrid films of $\mathrm{ZnO} / \mathrm{Ts}-\mathrm{CuPc}$ of various thicknesses are electrodeposited on ITO substrate and are characterized by X-ray diffraction (XRD), Atomic Force Microscopy (AFM) and Scanning Electron Microscopy (SEM). The optical and electrical properties of hetero-junction photovoltaic device consisting of hybrid organic (Ts-CuPc)-inorganic $(\mathrm{ZnO})$ structure thin film are presented. Aside from wavelength dependent photocurrent measurements, time-resolved photocurrent measurements are also discussed. Theoretical calculations based on DFT models have been made to study how the dye interacts with the surface and how the bands of the hybrid system are aligned. This is a crucial issue for knowing the possibilities of charge transfer between the donor and the acceptor. Therefore two main goals are addressed in the present paper; the preparation and characterization of hybrid TS-CuPc/ZnO thin films and the understanding of their photoelectronic properties by means of a theoretical level alignment calculation using DFT methods.

\section{Experimental}

High purity $\mathrm{ZnCl}_{2}, \mathrm{KCl}$ and $1 \alpha 3 \beta\left(\mathrm{NaSO}_{3}\right) \mathrm{CuPc}$ (here by referred as $\mathrm{Ts}-\mathrm{CuPc}$ ) dye from Aldrich chemicals were taken as starting materials. The experimental setup used to prepare $\mathrm{ZnO} / \mathrm{Ts}$-CuPc thin films of various thicknesses by cathodic electrodeposition technique was consisted of a computer-controlled potentiostat/ galvanostat and a classical three-electrode electrochemical cell filled with an aqueous solution containing $5.0 \mathrm{mM} \mathrm{ZnCl}_{2}$ and $0.1 \mathrm{M} \mathrm{KCl}$ as supporting electrolyte. Oxygen was bubbled through the solution to make it saturated with oxygen A glass coated with ITO substrate with sheet resistance of $10 \Omega$ /square, previously cleaned in an ultrasonic acetone bath for $15 \mathrm{~min}$ and then rinsed in distilled water and dried, was the working electrode. Pt and $\mathrm{Ag} / \mathrm{AgCl}$ electrodes were used as counter electrode and reference electrode, respectively. The deposition potential was fixed at $-0.9 \mathrm{~V}$ and the solution temperature was kept constant at $70^{\circ} \mathrm{C}$ by a thermostat. The concentration of dye in solution was varied from $10 \mu \mathrm{M}$ to $200 \mu \mathrm{M}$. The structural characterization of the hybrid films was done by high-resolution XRD using a Rigaku Ultima IV diffractometer through $\theta-2 \theta$ scans with copper anticathode ( $\mathrm{CuK} \alpha, 1.54 \AA$ ). The morphology of the films was studied by using a JEOL-JSM6300 scanning electron microscope operating at $10 \mathrm{kV}$. Optical transmittance measurements were performed by means of a deuterium-halogen lamp Ocean Optics DT-MINI-2-GS in association with a $500 \mathrm{~mm}$ spectrometer coupled to a back-thinned CCD detector optimised for the UV-vis range. The photoelectrochemical study was performed in a conventional three electrode arrangement in a glass cell with the deposited thin film as a window of the cell illuminated from the glass/ITO side and used as a working electrode, a Pt counter electrode and a $\mathrm{Ag} / \mathrm{AgCl}$ reference electrode with $0.1 \mathrm{M} \mathrm{KCl}$ as solvent. All measurements were performed at a $0.05 \mathrm{~V}$ with negligible dark current. The illumination time of the electrode was controlled using a automatic mechanical shutter, for which a controller box had been designed, adjusting the time of illumination to $10 \mathrm{~s}$. The shutter needed about $10 \mathrm{~ms}$ to reach a completely open (or closed) position. The photocurrent was measured with a potentiostat/galvanostat and recorded on the PC with proper software. All samples were scanned from $200 \mathrm{~nm}$ to $900 \mathrm{~nm}$ with an interval of $10 \mathrm{~nm}$.

\section{Theoretical}

Calculations based on density functional theory (DFT) were made using a PBE-GGA [28] functional. The used code was SIESTA [29], which projects electron wave functions and density onto a real space grid and uses as basis set a linear combination of numerical, finite-range localized atomic orbitals. We also used the DFT+U method [30] included in SIESTA that allows a semi-empirical inclusion of electronic correlations in the description of electronic spectra for systems such as zinc oxide. The used atomic basis set was a double zeta with polarization (DZP) obtained variationally [31] in a bulk $\mathrm{ZnO}$ reference, for zinc and oxygen, and using the phthalocyanine molecule itself for the rest of the elements. Core electrons were replaced by norm-conserving pseudo potentials [32]. The mesh cutoffs for real and reciprocal space were such that the energy was converged within $0.001 \mathrm{eV}$. It is important to keep in mind the limitations of DFT methods related to band gap underestimation. The theoretical results presented here should be taken as qualitative. In any case, DFT calculations are clearly useful in the characterization of the bonding between the dye and the nanostructure. This theoretical study can be seen as a first step to show that charge transfer is possible and to explain the experimental results presented here.

\section{Results and discussion}

\subsection{Crystallinity}

XRD patterns of ZnO films prepared with dye of different concentrations in electro-deposition bath varying from $10 \mu \mathrm{M}$ to $200 \mu \mathrm{M}$ at $-0.9 \mathrm{~V}$ of deposition potential at $70^{\circ} \mathrm{C}$ for all samples are shown in Fig. 2a and b. A total charge of $1.5 \mathrm{C}$ was passed in each case. It is well known that pure $\mathrm{ZnO}$ films show reflexions corresponding to the wurtzite structure, however, with strong $\left(\begin{array}{ll}0 & 0\end{array}\right)$ but weak $\left(\begin{array}{lll}1 & 0 & 0\end{array}\right)$ and $\left(\begin{array}{lll}1 & 0 & 1\end{array}\right)$ reflexions (Fig. 2a). The intensity of $(002)$ peak increases with the rise of deposition temperature and it maximizes at $60^{\circ} \mathrm{C}$ and $70^{\circ} \mathrm{C}$. This has been reported before for electrodeposited $\mathrm{ZnO}$ films [33,34]. The same orientation is still seen for the hybrid films deposited with $10 \mu \mathrm{M}-60 \mu \mathrm{M}$ concentration of dye in the electro-deposition bath. Going to high dye concentrations $(100 \mu \mathrm{M}$ and $200 \mu \mathrm{M})$ in the electro-deposition bath leads to the formation of amorphous films noticeable in 
disappearance of all ZnO peaks. But a more careful examination of the XRD patterns of the films grown at high concentration of dye (Fig. 2b) shows the retention of crystalline character. The size of crystallites for the films fabricated with different concentrations of dye was calculated by Scherrer's formula from the full with at half maximum (FWHM) of $(002)$ diffraction peaks (Fig. 3a). It may be observed that the size of the crystallites decreases as the concentration of dye increases in the film, till it becomes almost
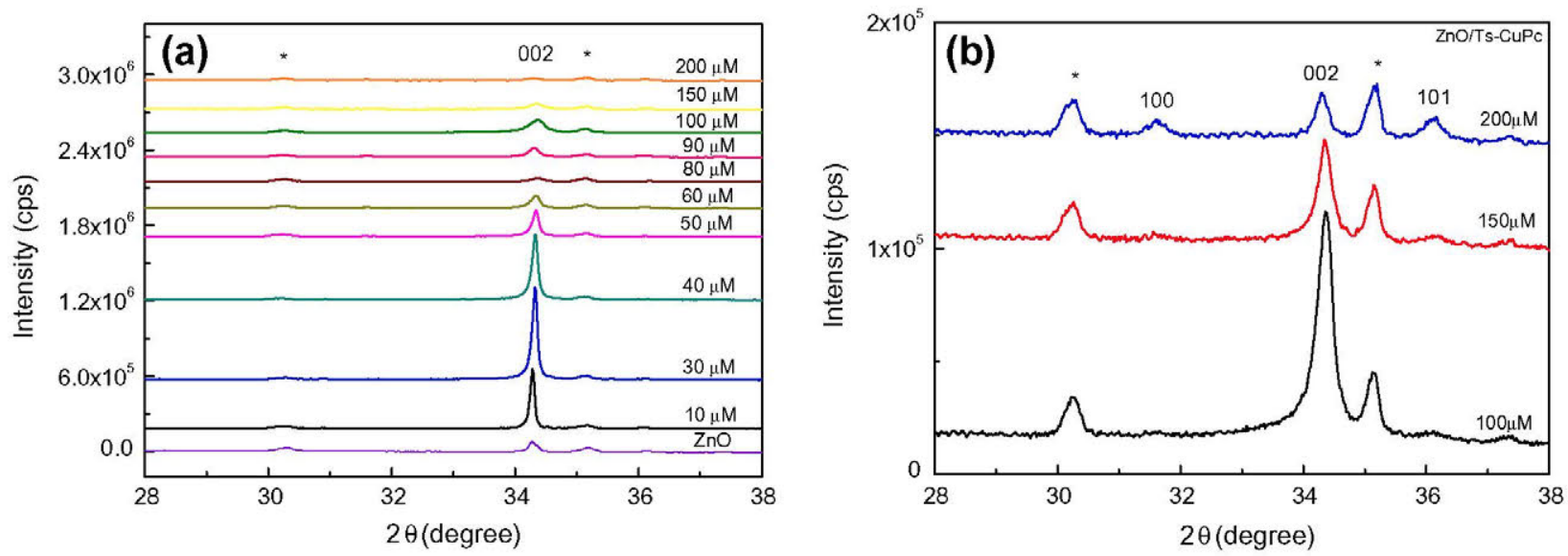

Fig. 2. (a) XRD patterns of ZnO/Ts-CuPc films deposited with $10 \mu \mathrm{M}$ to $200 \mu \mathrm{M}$ concentration of dye in deposition bath, $T=70^{\circ} \mathrm{C}, V=-0.9 \mathrm{~V}, \mathrm{Q}=-1.5 \mathrm{C}$; (b) Zoom of the XRD patterns of hybrid films with high dye content. ITO peaks are labeled as *.
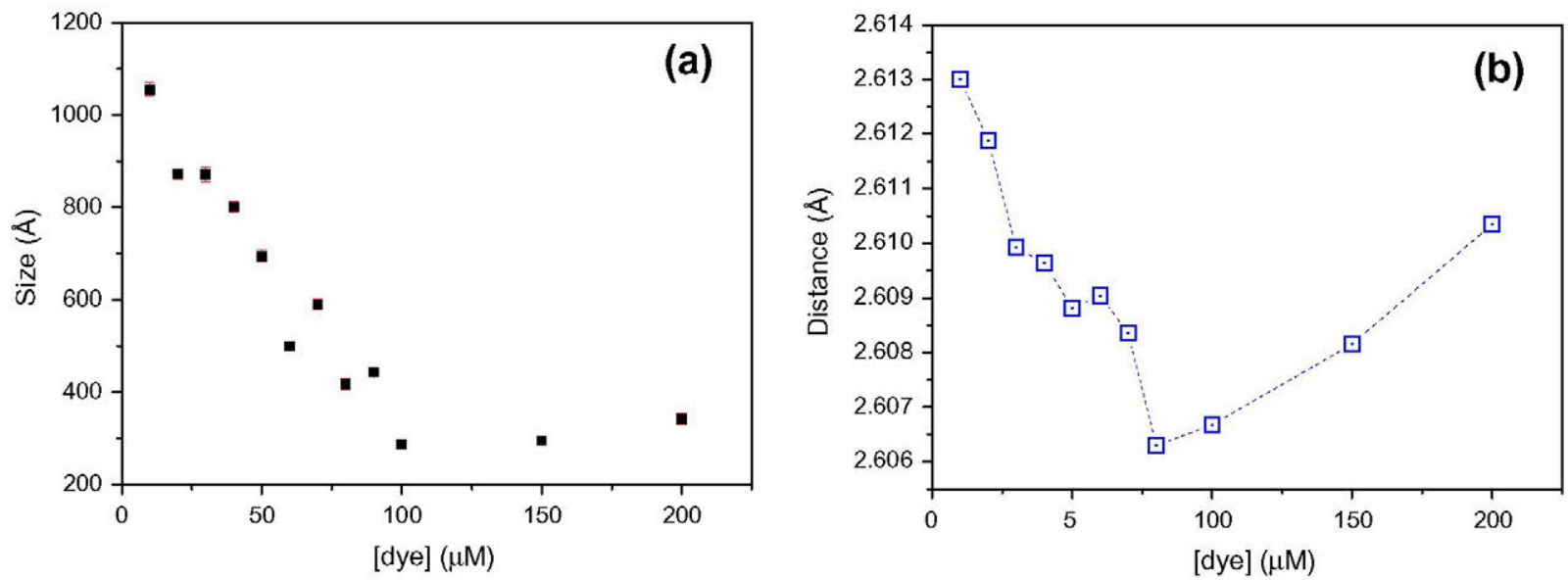

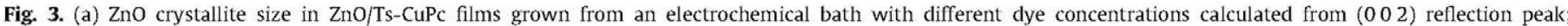
(b) Variation of distance of crystal planes along the $(002)$ direction as a function of the dye concentration.
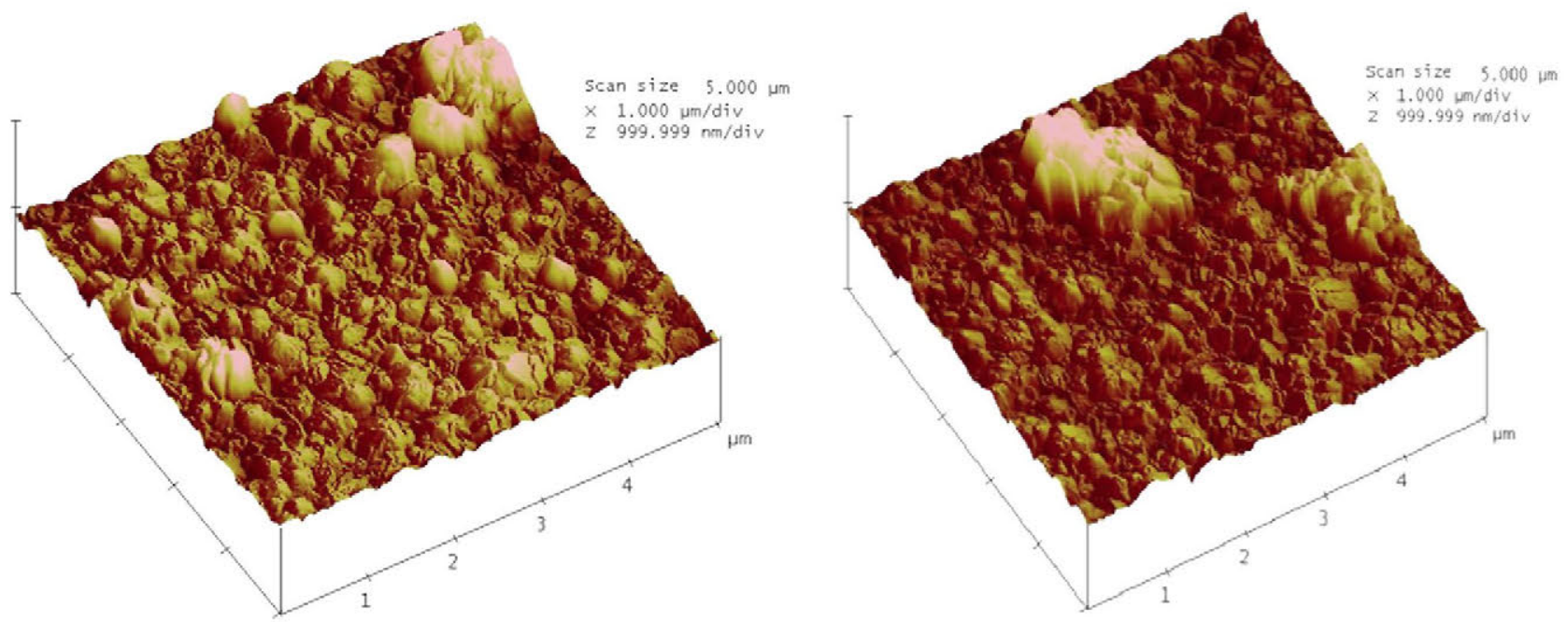

Fig. 4. AFM images of the $\mathrm{ZnO} / \mathrm{Ts}-\mathrm{CuPc}$ hybrid films. 
constant about $50 \mathrm{~A}$ with dye concentration more than $100 \mu \mathrm{M}$ This clearly indicates that more is the concentration of dye in the electrolytic bath, more porous film of $\mathrm{ZnO}$ is formed and which has the more capacity of adsorption of dye on the surface. But the increase of dye concentration beyond $100 \mu \mathrm{M}$ not affects the porosity of the film. Fig. 3b depicts the interplanar distance between the adjacent crystal planes calculated from the position of the $\left(\begin{array}{lll}0 & 0 & 2\end{array}\right)$ diffraction peak. The interplanar distance between (0 02 ) planes varies from 2.606 to $2.613 \AA$, which are slightly higher than the standard $\mathrm{ZnO}$ crystals (2.600 A). The distance between the reflection planes decreases as the crystallite size of $\mathrm{ZnO}$ decreases. But when the dye concentration is more than $100 \mu \mathrm{M}$ the increase of distance in the reflection planes is due to the large number of associated dye molecules on $\mathrm{ZnO}$ surface.

Fig. $4 \mathrm{a}$ and $\mathrm{b}$ shows the AFM micrograph of a $5 \times 5 \mu \mathrm{m}$ area for porous $\mathrm{ZnO}$ film grown in a bath containing $10 \mu \mathrm{M}$ concentration of dye. It may be observed that the $\mathrm{ZnO}$ surface is porous and most of the pores are interconnected and surface is rough but continuous.
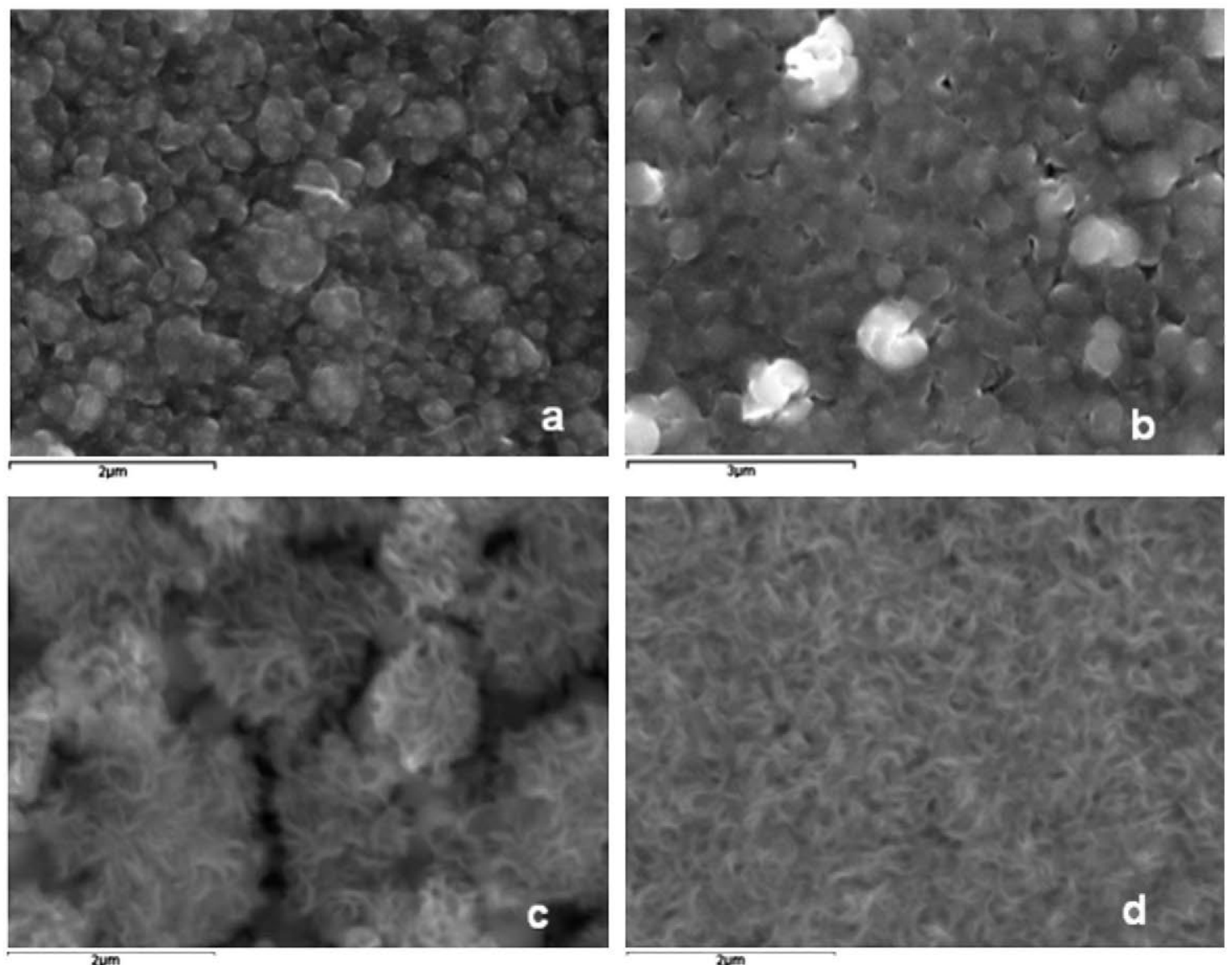

Fig. 5. SEM micrographs of $\mathrm{ZnO} / \mathrm{Ts}$-CuPc films with different concentration of dye in deposition bath. (a) $10 \mu \mathrm{M}$, (b) $20 \mu \mathrm{M}$, (c) $100 \mu \mathrm{M}$ and (d) $150 \mu \mathrm{M}$.
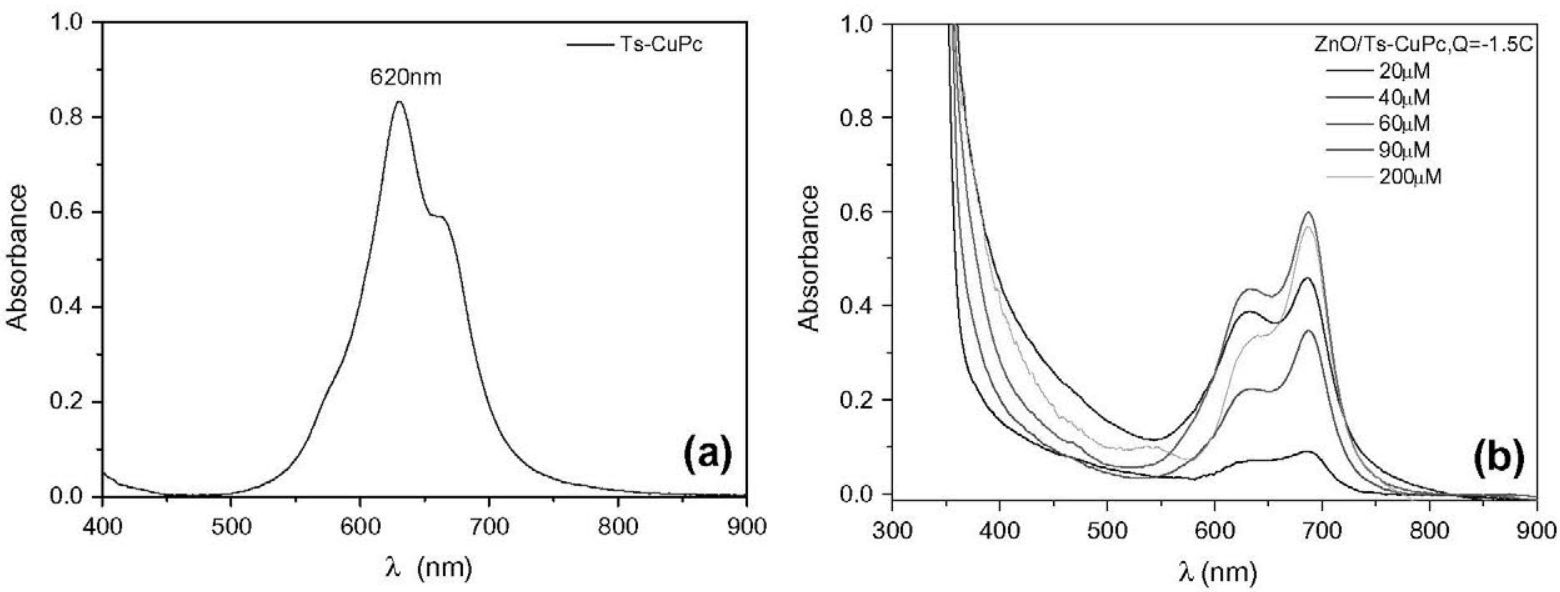

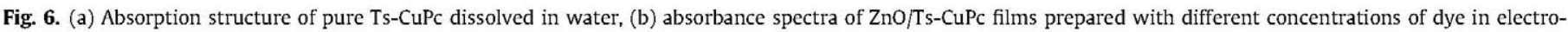
deposition bath at $T=70^{\circ} \mathrm{C}, V=-0.9 \mathrm{~V}$ and $\mathrm{Q}=-1.5 \mathrm{C}$. 
Fig. 5a-d shows top view SEM images of films grown with $10 \mu \mathrm{M}$, $20 \mu \mathrm{M}, 100 \mu \mathrm{M}$ and $150 \mu \mathrm{M}$ Ts-CuPc in the electro-deposition bath, i.e., the fully crystalline film with the highest crystallographic orientation and almost amorphous film with the large dye content. The crystalline character of the films with lower dye content is clearly seen in Fig. 5a and b in the appearance well defined hexagonal crystallites of similar sizes, but the porosity of the film grown with $20 \mu \mathrm{M}$ Ts-CuPc is more than that of grown in $10 \mu \mathrm{M}$ Ts-CuPc. By contrast, the surface of the film with high dye concentration looks more continuous and smoother.

\subsection{Optical analysis}

In Fig. $6 \mathrm{a}$ and $\mathrm{b}$ the absorption spectra of pure Ts-CuPc dissolved in water and of $\mathrm{ZnO} / \mathrm{Ts}$-CuPc films electro deposited with Ts-CuPc concentrations of $20 \mu \mathrm{M}, 40 \mu \mathrm{M}, 60 \mu \mathrm{M}, 90 \mu \mathrm{M}, 150 \mu \mathrm{M}$ and $200 \mu \mathrm{M}$ in the electro-deposition bath are presented and compared. The absorption spectrum of pure Ts-CuPc dissolved in water shows a strong peak of dimeric Ts-CuPc at $620 \mathrm{~nm}$ and a shoulder at $660 \mathrm{~nm}$, which indicates the presence of some monomeric Ts-CuPc molecules. The strong p-electron interaction between Ts-CuPc molecules leads to the formation of dimmers by face-toface arrangement of the phthalocyanine rings in the solution $[35,36]$. Apart from a blueshift of the strong dimmer peak to $630 \mathrm{~nm}$ and monomeric peak to $690 \mathrm{~nm}$, the spectra of $\mathrm{ZnO} / \mathrm{Ts}$-CuPc films exhibit the increase of absorption intensity with increase of dye concentration in the electrolytic bath. Strong absorption peaks at $630 \mathrm{~nm}$ and $690 \mathrm{~nm}$ show the incorporation of both monomer and dimmer form in $\mathrm{ZnO}$. But when the high concentration of dye like $200 \mu \mathrm{M}$ are used for deposition, there is a decrease of absorption intensity of both peaks showing the presence of aggregates of dye molecules within the crystalline layers and some of them do not contribute to the absorption of light. All films exhibit a high transparency regardless of the dye content.

\subsection{Photoelectrochemical study}

In Fig. 7 the photocurrent spectra are shown for films prepared in $30 \mu \mathrm{M}, 40 \mu \mathrm{M}, 70 \mu \mathrm{M}$ and $100 \mu \mathrm{M}$ dye concentration in the electrolytic bath. The photocurrent spectrum roughly follows the absorption spectrum of the $\mathrm{ZnO}$ film and absorption spectrum of dye to contribute to the photocurrent. The longer wavelength absorption at $680 \mathrm{~nm}$ dominated the contribution to the photocurrent due to monomeric dye. It is confirmed that the photocurrent is caused by absorption in the adsorbed dye and subsequent sensitization of $\mathrm{ZnO}$. This is well in line with earlier observations that this monomeric absorption provides clearly enhanced quantum efficiency because of a decreased probability of radiationless decay when compared with the aggregate absorption band at $650 \mathrm{~nm}$ [27,37].

Only in films with dye concentration lower than $40 \mu \mathrm{M}$ the contribution of both $\mathrm{ZnO}$ and dye to the photocurrent spectra can be observed. For higher dye concentrations the photocurrent due to the dye is not longer observed and the contribution due to $\mathrm{ZnO}$ tends to vanish. In Fig. 7a small photocurrent owing to $\mathrm{ZnO}$ contribution in the $340 \mathrm{~nm}$ region is still observed for $70 \mu \mathrm{M}$ dye concentration film but no photocurrent is observed in the hybrid film grown with $100 \mu \mathrm{M}$ concentration of dye in the total range of light scan from $200 \mathrm{~nm}$ to $900 \mathrm{~nm}$. This again confirms the total coverage of dimmer or associated species of dye on $\mathrm{ZnO}$ surface, of course dye molecules absorb the radiations but the energy is relaxed in the radiation less decay. The surface of $\mathrm{ZnO}$ particles is totally covered by the associated dye molecules that no radiation $(340 \mathrm{~nm})$ is able to reach the Zno surface. The hybrid films with high dye content behaves like a thin film of pure Ts-CuPs.

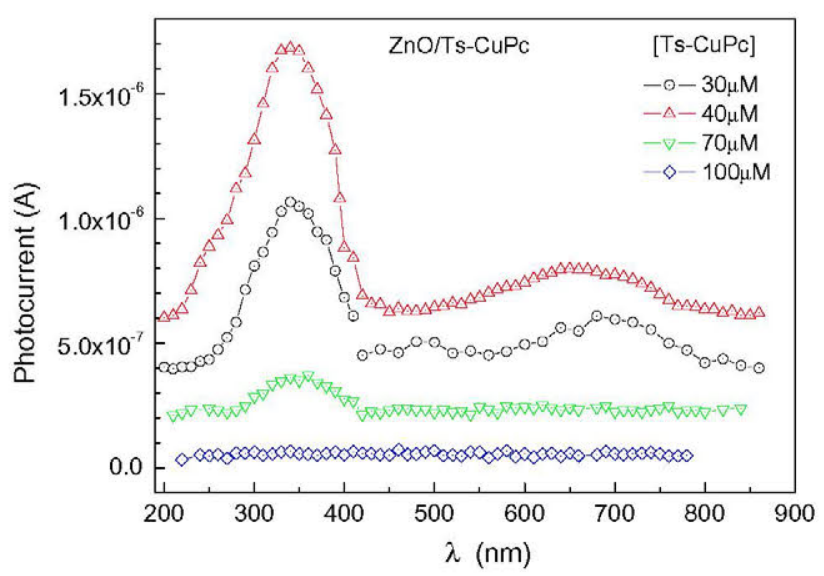

Fig. 7. Photocurrent action spectra of $\mathrm{ZnO} / \mathrm{Ts}-\mathrm{CuPc}$ films electrodeposited with $30 \mu \mathrm{M}, 40 \mu \mathrm{M}, 70 \mu \mathrm{M}$ and $100 \mu \mathrm{M}$ concentrations of dye.

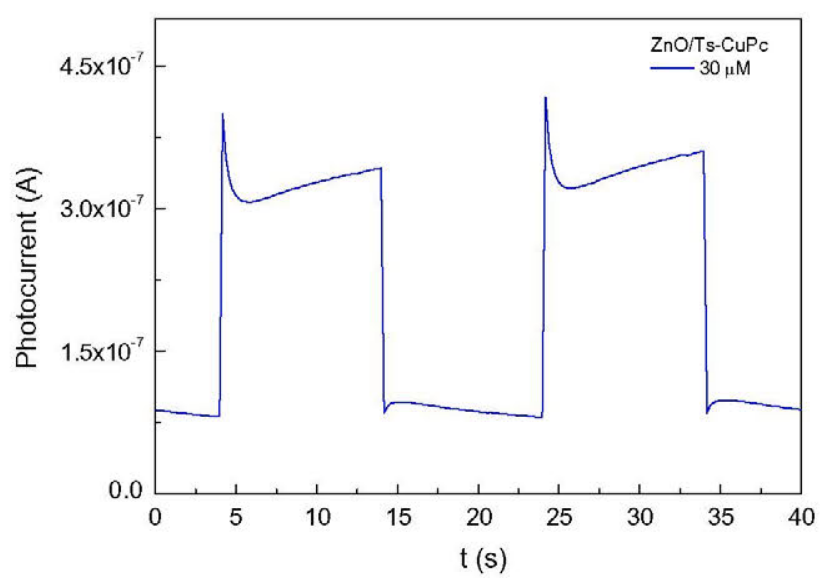

Fig. 8. Time-resolved photocurrent measured for the $\mathrm{ZnO} / \mathrm{Ts}$-CuPc films electrodeposited with $30 \mu \mathrm{M}$ concentration of dye.

The films of $30 \mu \mathrm{M}$ and $40 \mu \mathrm{M}$ dye concentrations show a far too low photocurrent to be of technical interest. Time-resolved photocurrent measurements were used to further elucidate the origin of such low efficiency (Fig. 8). Hybrid films of $\mathrm{ZnO} / \mathrm{Ts}-\mathrm{CuPc}$ clearly showed an overshoot upon opening of the shutter characteristic of a slow regeneration reaction [27,37] of the oxidized dye molecule following fast injection to $\mathrm{ZnO}$, typically caused by poor accessibility of sensitizers by the redox electrolyte and leading to a steady-state concentration of oxidized sensitizer representing a positively charged interface (electrode negative). Such a situation leads to increased recombination of charge carriers and hence a small photocurrent. Upon shutter closure, this recombination is directly observed in a small cathodic spike, representing the discharge of the positive surface charge by electrons from the electrode (hence opposite direction of current) [38].

\subsection{DFT calculations}

The theoretical procedure was the following. First, various nano-structures of $\mathrm{ZnO}$ and the Ts-CuPc molecule were separately modeled. This was the previous step before studying their interaction. $\mathrm{ZnO}$ bulk structure was studied and its lattice parameters and atomic positions were obtained from theory by minimizing the energy. As $\mathrm{ZnO}$ and hybrid films have presented a $\left(\begin{array}{lll}0 & 0 & 2\end{array}\right)$ orientation (see Fig. 2), it was assumed that the available faces for the dye 
would be perpendicular to this direction. The selected likely face for docking the dye to $\mathrm{ZnO}$ was the wurtzite $(100)$ face. Thus, slices of different widths were generated in the $\mathrm{ZnO}\left(\begin{array}{lll}1 & 0 & 0\end{array}\right)$ direction, which are periodic in the $(001)$ and $(1-20)$ perpendicular directions. The band gap width found was $1.1 \mathrm{eV}$ for the $\mathrm{ZnO}$ slab, lower than the experimental one, $3.43 \mathrm{eV}$. This is a well-known underestimation in DFT calculations. However, the valence band levels are correctly placed when using the DFT+U approach, so a rigid shift of conduction band levels would take the proper gap. Parallel to the study of the $\mathrm{ZnO}$ structure, the Ts-CuPc molecule (Fig. 1) was studied, finding its optimum geometry and higher occupied molecular orbital energy (HOMO) and lowest unoccupied energy (LUMO). The molecule is flat except the sulphonic groups which can freely rotate. The effect of these groups on the interaction with the nanostructure appeared to be very important for the bonding and not only for the molecule solubility. We then studied the interaction of the two previously converged structures by performing joint relaxations starting from different candidate bound geometries. This analysis is crucial because efficiencies of solar cells depend on organic dyes to bind optimally to the surface of the nano-structure. We have studied three types of interactions between molecule sulphonic acids and the surface. In two of them the Ts-CuPc orientation was parallel to the surface and in the last the interaction was perpendicular. Results showed that the most stable orientation was parallel to the surface with eight sulphonic oxygens, bound to zinc atoms. Furthermore, a $\mathrm{Cu}-\mathrm{O}$ interaction appeared, moving the metal atom beyond the plane of the molecule. Once the preferential orientation was found, total and projected densities of states were computed for this hybrid system. The Ts-CuPc HOMO was found $0.2 \mathrm{eV}$ above the $\mathrm{ZnO}$ valence band. A good estimate of band alignments between adsorbate and substrate was achieved with DFT+U, using the correlation corrections that gave good spectra for both systems separately. Results showed (Fig. 9) that the Ts-CuPc LUMO appears inside the nanostructure gap, so that a direct charge transfer between the donor and the acceptor does not seem possible. The LUMO+1 level appears almost

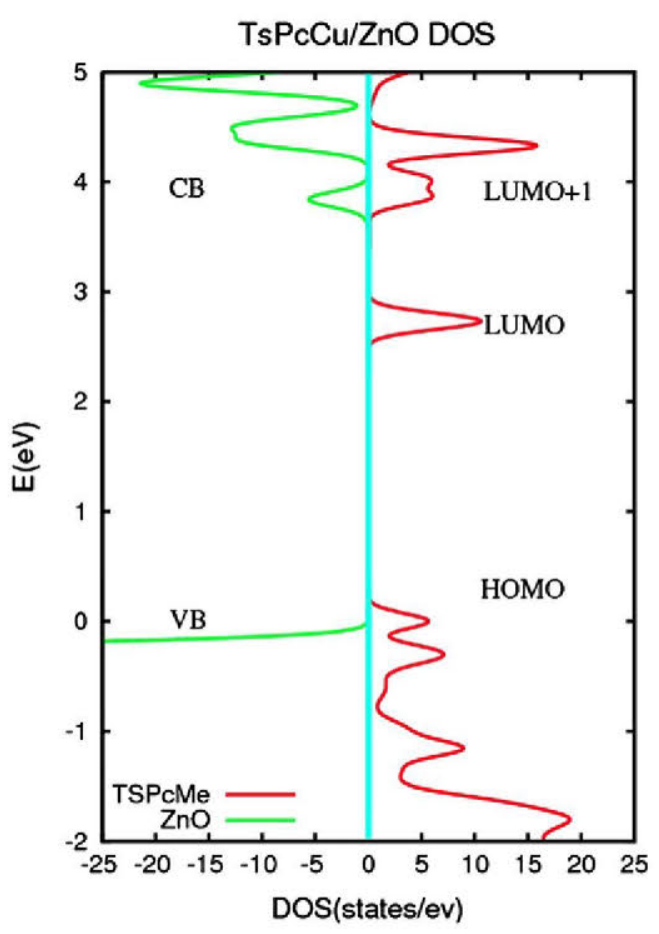

Fig. 9. DFT Projected Density of states for the ZnO/Ts-CuPc hybrid system. The Fermi level is aligned with $\mathrm{ZnO}$ valence band. at the same energy level than the $\mathrm{ZnO}$ conduction band, suggesting that, if some charge transfer does happen, it should be small and through a LUMO+1 molecular excitation.

\section{Conclusions}

Electrodeposited $\mathrm{ZnO} / \mathrm{Ts}-\mathrm{CuPc}$ films represent a hybrid material system that can be varied in its contents in a wide range simply by variation of the Ts-CuPc concentration in the electro-deposition bath. At the same time, the optical as well as the electrical and photoelectrical properties can be tuned. Electrodeposited hybrid films with high phthalocyanine content behave as a thin film of Ts-CuPc. Photocurrent can only be generated in the films having a low concentration of dye. The probable reasons of an over shoot in the photocurrent at the beginning of illumination and a cathodic spike when the illumination was cut off are discussed and related with the low efficiency of photocurrent generation. Theoretical calculations based on DFT models have been made to understand the optoelectronic properties of the hybrid films. Results showed that Ts-CuPc LUMO appears inside the nanostructure gap, so a charge transfer between the donor and the acceptor is not possible. LUMO+1 level appears almost at the same energy level that $\mathrm{ZnO}$ conduction band. So if some charge transfer is possible, it should be small and due to a LUMO+1 molecular excitation.

\section{Acknowledgments}

Spanish Government supported this work through MEC Grant MAT2009-14625-C03. M. Moya acknowledges the GeneralitatValenciana (Santiago Grisolia Program) for fellowship funding. P. Palacios acknowledges the hospitality of the Earth Sciences Department in Cambridge. The authors acknowledge the computer resources provided by the Madrid Supercomputing Center (CeSViMa).

\section{References}

[1] G.D. Sharma, R. Kumar, S.K. Sharma, M.S. Roy, Sol. Energy Mater. Sol. Cells 90 (2006) 933-943.

[2] G. Ferraudi, in: C.C. Leznoff, A.B.P. Lever (Eds.), Phthalocyanines, Properties and Applications, vol. 1, VCH, New York, 1989, pp. 293-340.

[3] J.H. Zagal, S. Griveau, J.F. Silva, T. Nyokong, F. Bedioui, Coord.Chem. Rev. 2010 in press. doi: $10.1016 /$ jccr.2010.05.001.

[4] I. Rosenthal, E. Ben-Hur, in: C.C. Leznoff, A.B.P. Lever (Eds.), Phthalocyanines, Properties and Applications, vol. 1, VCH, New York, 1989, pp. 7-427.

[5] R. Bonnett, Chem. Soc. Rev. 24 (1995) 19.

[6] B.O. Regan, M. Grätzel, Nature 353 (1991) 737-740.

[7] M.K. Nazeeruddin, A. Kay, I. Rodicio, R. Humphry-Baker, E. Muller, P. Liska, N. Vlachopoulos, M. Grätzel, J. Am. Chem. Soc. 115 (1993) 6382.

[8] A. Hagfeldt, M. Grätzel, Chem. Rev. 95 (1995) 49-68.

[9] M.K. Nazeeruddin, P. Pechy, T. Renouard, S.M. Zakeeruddin, R. Humphry-Baker, P. Comte, P. Liska, L. Cevey, E. Costa, V. Shklover, L. Spiccia, G.B. Deacon, C.A. Bignozzi, M. Grätzel, J. Am. Chem. Soc. 123 (8) (2001) 1613-1624.

[10] M.K. Nazeeruddin, E. Muller, R. Humphry-Baker, N. Vlachopoulos, M. Grätzel, J.Chem. Soc. Dalton Trans. (1997) 4571-4578.

[11] M. Alexander, W. Thomspon, M. Smailes, J. Jeffery, M. Ward, J. Chem. Soc. Dalton Trans. (1997) 737-745.

[12] M.K. Nazeeruddin, S.M. Zakeeruddin, R. Humphry-Baker, M. Jirousek, P. Liska, N. Vlachopoulos, V. Shklover, C.H. Fischer, M. Grätzel, Inorg. Chem. 38 (1999) 6298-6305.

[13] C. Chen, X. Qi, B. Zhou, J. Photochem. Photobiol. A 109 (1997) 155-158.

[14] E. Ghenne, F. Dumont, C. Buss-Herman, Colloid Surf. A 131 (1-3) (1998) 63-67.

[15] V. Kamat, J. Phys. Chem. 93 (1989) 859-864.

[16] Y. Tachibana, S.A. Haque, I.P. Mercer, D.R. Klug, J.R. Durrant, J. Phys. Chem. B 104 (2000) 1198-1205.

[17] J. Asbury, E. Hao, Y. Wang, H. Ghosh, T. Lian, J. Phys. Chem. B 105 (2001) 45454557.

[18] K. Kudo, T. Moriizumi, Jpn. J. Appl. Phy. 19 (1980) 2683.

[19] S.M. Tracey, A.K. Ray, T.S. Shishiyanu, IEE Proc Circ. Dev. Syst. 145 (1998) 383.

[20] D. Schlettwein, Photoelectrochemical Reactions at Phthalocyanine Electrodes, in: J.H. Zagal, F. Bedioui F, J.P.Dodelet (Eds.) N-4 Macrocyclic Complexes, Springer, New York, 2006 and references therein.

[21] T. Yoshida, H. Minoura, Adv. Mater. 12 (2000) 1219 
[22] (a) K. Nonomura, T. Yoshida, D. Schlettwein, H. Minoura, Electrochim. Acta 48 (2003) 3071;

(b) T. Oekermann, S. Karuppuchamy, T. Yoshida, D. Schlettwein, D. Wöhrle, H. Minoura, J. Electrochem. Soc. 151 (2004) C62.

[23] T. Yoshida, Electrochemistry 72 (2004) 44.

[24] T. Yoshida, K. Miyamoto, N. Hibi, T. Suguira, H. Minoura, D. Schlettwein, T. Oekermann, G. Schneider, D. Wöhrle, Chem. Lett. (1998) 599.

[25] T. Yoshida, M. Tochimoto, D. Schlettwein, D. Wöhrle, T. Suguira, H. Minoura, Chem. Mater. 11 (1999) 2657.

[26] T. Pauporte, F. Bedioui, D. Lincot, J. Mater. Chem. 15 (2005) 1552.

[27] D. Schlettwein, T. Oekermann, T. Yoshida, M. Tochimoto, H. Minoura, J. Electroanal. Chem. 481 (2000) 42.

[28] J.P. Perdew, K. Burke, M. Ernzerhof, Phys. Rev. Lett. 77 (1996) 3865; 78 (1997) 1396 (E).

[29] J.M. Soler, E. Artacho, J.D. Gale, A. García, J. Junquera, P. Ordejón, D. SănchezPortal, J. Phys.: Condens. Matter 14 (2002) 2745-2779;

E. Artacho, E. Anglada, O. Dieguez, J.D. Gale, A. García, J. Junquera, R.M. Martin, P. Ordejón, J.M. Pruneda, D. Sánchez-Portal, J.M. Soler, J. Phys.: Condens. Matter $20(2008) 064208$.
[30] S.L. Dudarev, G.A. Botton, S.Y. Savrasov, C.]. Humphreys, A.P. Sutton, Phys. Rev. B 57 (1998) 1505.

[31] E. Anglada, J.M. Soler, J. Junquera, E. Artacho, Phys. Rev. B 66 (2002) 205101

[32] N. Troullier, J.L. Martins, Phys.Rev. B 43 (1991) 1993.

[33] Harald Graaf, Carsten Maedler, Mirko Kehr, Torsten Oekermann, J. Phys. Chem. C 113 (2009) 6910.

34] C. Boeckler, T. Oekermann, M. Soruban, K. Ichinose, T. Yoshida, Phys. Stat. Sol 205 (2005) 2388.

[35] G. Ferraudi, Phthalocyanines Properties and Applications, in: C.C. Leznoff, A.B.P. Lever (Eds.), vol. 4, Wiley-VCH, New York, 1998.

[36] C.F. van Nostrum, R.J.M. Nolte, Chem. Commun. (1996) 2385.

37] T. Oekermann, T. Yoshida, D. Schlettwein, T. Sugiura, H. Minoura, Phys. Chem. Chem. Phys. 3 (2001) 3387.

[38] L.M. Peter, Chem. Rev. 90 (1990) 753. 